\title{
A Scientific Saga
}

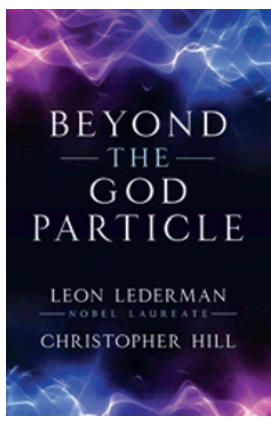

Beyond the

God Particle

By Leon Lederman and

Christopher Hill

PROMETHEUS: 2013.

325PP. $\$ 24.95$

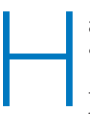

aving arrived at the moniker

'God particle' in Leon Lederman's

previous popular science book from

20 years ago, it is clear that the authors

of its sequel, Beyond the God Particle,

understand how this provokes people.

The possibility of a 'Satan particle' and of

'Mass' being more an ecumenical matter

are deftly handled at the start of the book,

where Norse mythology plays a part: the

Nibelungen experimenters are now seen

as toiling for the past 20 years towards the

Large Hadron Collider (LHC) ring, and

the 4 July 2012 event at CERN, where the

ATLAS and CMS experiments made their

historic announcements as the start of a saga.

Lederman and Hill manage to describe the mechanism for mass generation, the methods required to build particle accelerators, the motivation for scientific endeavour and the name God particle in 300 captivating pages. With apparent ease they entertain while telling us how we came to understand our Universe in the past, what we know now and how we may go about understanding it in the future. Their answers to the big questions are well grounded in the scientific method, resisting any temptation for conjecture and conveyed with a youthful enthusiasm for the way things work that is difficult to resist. In a compelling page-turning narrative they reveal wideranging and important insights into the remaining mysterious puzzles of the physical world in an authoritative yet lighthearted way.

The mechanism for mass generation becomes a tall tale of big fish (mountain lakes full of rainbow trout). We're carefully led up the mountain, understanding how left- and right-handed fields are distinguished in electroweak theory. In this lake, the left-handed and the right-handed particles are seen to be oscillating at close to the speed of light, but only the left-handed ones carry the crucial weak charge. The pervasive Higgs field also carries this weak charge, enabling transitions between the leftand the right-handed particles, and it is in these transitions that the origin of mass arises.

The section on the methods required to build particle accelerators begins with the earliest developments of microscopes and their inextricable link with telescopes. These techniques are brought fully up to date with the LHC, where the evolution of the methods using radio-frequency cavities to accelerate and magnets to bend and focus the particle beams is seen as a stepping stone to the future. The starting point for the chapter on the world's most powerful accelerators is the meeting where William Gladstone asks where all that "wasteful spending" is going and Michael Faraday responds "I don't know what good this will be, but one day you may tax it". In this context the motivation for the pursuit of science is seen as driven by technological challenges that subsequently power the economies of great nations. The techniques employed in developing the world's largest microscopes and analysing the associated data are recognized from a historical perspective as investments for the future.

The book conveys the importance of long-term investments in infrastructure at the high-intensity, as well as the high-energy bounds of particle physics. The difficulties in pushing technology to its limit are brought home in the story of the commissioning of the LHC. The experimental evidence for a Higgs Boson is recognized as being of far-reaching consequence in our understanding of the Universe, but for the politicians the questions are frequently about return on (large) investments. Repeated historical examples illustrate how the gains may be long- or short-term, but in the end the wealth of nations becomes inextricably linked to answering big questions such as the origin of mass.

This saga is well worth the journey: the book will stir people up for all the right reasons and is recommended reading for all those interested in the largest scales of human endeavour.

\section{REVIEWED BY TONY DOYLE}

Tony Doyle is at the Scottish Universities Physics Alliance, School of Physics and Astronomy, University of Glasgow, Glasgow G12 8QQ, UK. e-mail:tony.doyle@glasgow.ac.uk

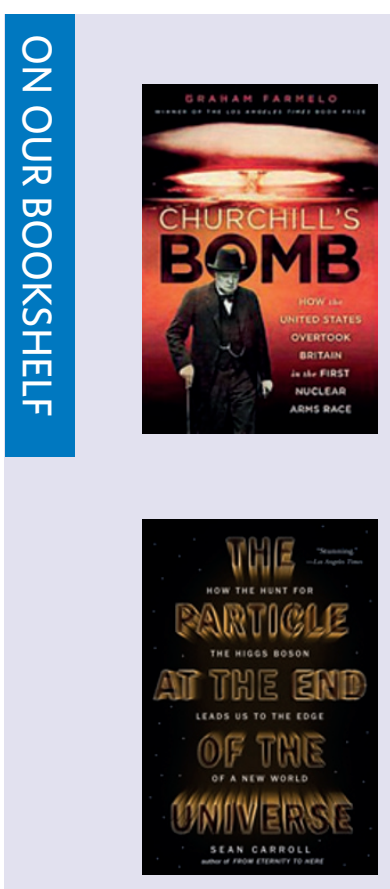

Churchill's Bomb: How the United States Overtook Britain in the First Nuclear Arms Race

By Graham Farmelo BASIC BOOKS: 2013. 544PP. \$29.99

We all know the outcome of the Manhattan Project, which effectively ended the Second World War. But few of us are aware of Britain's early lead in the development of the hydrogen bomb, or of Churchill's prescience when it came to nuclear warfare.

The Particle at the End of the Universe: How the Hunt for the Higgs Boson Leads Us to the Edge of a New World

By Sean Carroll

PLUME: 2013. 368PP. \$17

The extraordinary story of how experimental particle physicists caught up with the theoreticians, and how the Large Hadron Collider will allow them to take the lead and go beyond the standard model. 